\title{
Algoritma FCD dan NFT Pada Sistem Pencernaan Berbasis AR Menggunakan Single Marker
}

\author{
Akhmad Arief Mohajerani ${ }^{1}$, auziah $^{2}$, Aris Gunaryati ${ }^{3}$ \\ ${ }^{1}$ Jurusan Informatika, Fakultas Teknologi Komunikasi dan Informatika, Universitas Nasional \\ ${ }^{2,3}$ Fakultas Teknologi Komunikasi dan Informatika, Universitas Nasional \\ e-mail: ${ }^{1}$ akhmadariefm145@gmail.com, ${ }^{2}$ fauziah@ @ivitas.unas.ac.id, \\ 3aris.gunaryati@civitas.unas.ac.id
}

\begin{abstract}
Abstrak
Manusia diciptakan dengan berbagai sistem yang memiliki kemampuan yang berbedabeda, mulai dari sistem pernapasan, sistem pencernaan, sistem peredaran darah dan juga sistem ekskresi. Dari beban kerangka ini ada berbagai organ yang juga memiliki tugas yang berbeda. Namun, tidak sedikit orang yang tidak tahu apa-apa tentang kerangka dan organ apa yang ada di dalam tubuh, misalnya apa saja organ dan fungsi yang terkait dengan sistem pencernaan. Dalam penelitian ini, akan membidik pada organ-organ dalam kerangka terkait pencernaan manusia. Agar lebih menarik untuk dipelajari, pencipta akan memperkenalkan organ-organ ini sebagai aplikasi augmented reality. Eksplorasi ini diarahkan untuk memberikan pemahaman tentang organ dan fungsi apa yang ada dalam kerangka terkait pencernaan manusia. Dalam penelitian ini menggunakan strategi Single Marker, dengan desain aplikasi sistem, yaitu model waterfall yang terdiri dari analisis, desain, implementas, pengujian dan pemeliharaan dan menggunakan Fats Corner Detection (FCD) dan Natural Future Trackingx (NFT). Hasil pengujian dengan tiga device, jarak terdekat untuk menampilkan objek adalah $\pm 12 \mathrm{~cm}$ sedangkan jarak terjauh adalah $80-100 \mathrm{~cm}$. Terlebih lagi, hasil tes yang bergantung pada waktu respon untuk memunculkan artikel $3 d$ pada tiga device membutuhkan waktu di bawah 2 detik.
\end{abstract}

Kata kunci-3D Objek, Augmented Reality, Deteksi Marker, Media Pembelajaran, Sistem Pencernaan Manusia.

Humans were created with various systems that have different abilities, ranging from the respiratory system, digestive system, circulatory system and also the excretory system. From the weight of this skeleton there are various organs that also have different tasks. However, not a few people do not know anything about the skeleton and what organs are in the body, for example, what are the organs and functions related to the digestive system. In this study, we will focus on the organs in the human digestive system. To make it more interesting to study, the creators will introduce these organs as an augmented reality application. This exploration is aimed at providing an understanding of what organs and functions exist in the framework related to human digestion. In this study using a Single Marker strategy, with a system development model, namely the waterfall model consisting of analysis, design, implementation, testing and maintenance and using Fats Corner Detection (FCD) and Natural Future Trackingx (NFT). The results of the test with three devices, the closest distance to display objects is \pm 12 $\mathrm{cm}$ while the farthest distance is $80-100 \mathrm{~cm}$. What's more, test results that depend on response times to render $3 d$ articles on three devices took under 2 seconds.

Keywords-3D Objects, Augmented Reality, Marker Detection, Learning Media, Human Digestive System. 


\section{PENDAHULUAN}

$\mathrm{M}$ anusia diciptakan oleh Tuhan dengan berbagai macam sistem yang memiliki fungsi yang berbeda, mulai dari sistem pencernaan sampai sistem ekskresi. Dari semua sistem tersebut ada berbagai macam organ juga yang memiliki peran yang berbeda. Namun tidak sedikit manusia yang belum mengetahui apa saja sistem dan organ apa saja yang ada didalam tubuhnya, misalnya organ - organ apa saja yang ada di sistem pencernaan dan juga fungsi dari organ - organ tersebut. Pada pelitian ini akan berfokus kedalam organ - organ yang ada didalam sistem pencernaan manusia. Agar lebih menarik untuk pembelajaran, penulis akan menyajikan organ - organ tersebut dalam berupa aplikasi augmented reality. Sistem pencernaan ialah tahap dimana pengubah makanan yang telah dimakan mulai dari yang berukuran besar menjadi berukuran yang kecil agar bisa dicerna [1].

Pada penelitian sebelum ini dilakukan penelitian dengan judul Penerapan Augmented Reality Sebagai Media Pembelajaran Sistem Pencernaan pada Manusia yang memiliki manfaat untuk siswa SMA, yang telah memperoleh materi pembelajaran sistem pencernaan manusia [2]. Pada penelitian terdahulu menggunakan augmented reality dengan judul Implementasi Animasi Augmented Reality untuk Pelestarian Situs Bersejarah di Kabupaten Subang yang bertujuan untuk melakukan objek tracking secara real-time menggunakan algoritma NFT[3]. Kemudian pada penelitian lainnya telah dilakukan penelitian dengan judul Pengembangan Media Pembelajaran Mengenal Organ Pencernaan Manusia Menggunakan Teknologi Augmented Reality yang ditulis oleh Rujianto dkk yang mengasilkan sebuah aplikasi berbasis AR dengan menggunakan metode markerless.

Dari masalah dan kesempatan dari penelitian - penelitian diatas, maka penelitian yang dilakukan kali ini ialah membuat aplikasi Augmented Reality dengan metode Waterfall sebagai langkah - langkah pengembangan secara sistematis dan interaktif dengan menggunakan algoritma fats corner detection (FCD) dan juga Natural Future Tracking (NFT) yang digunakan untuk mengidentifikasi sudut - sudut tepi dan melacak arah objek 3 dimensi sehingga aplikasi sistem pencernaan dapat terealisasi dengan baik.

\section{METODE PENELITIAN}

\subsection{Augmented Reality (AR)}

Augmented reality (AR) ialah aplikasi yang mengkombinasikan dua dunia, yaitu dunia real dan dunia fana baik dalam dua dimensi ataupun tiga dimensi yang kemudian ditampilkan didunia real pada waktu bersamaan [4].

\section{2 Waterfall Model}

Metode waterfall adalah sebuah model desain aplikasi sistem informasi yang teratur dan bertahap [5]. Berikut adalah tahapan dari metode waterfall: 


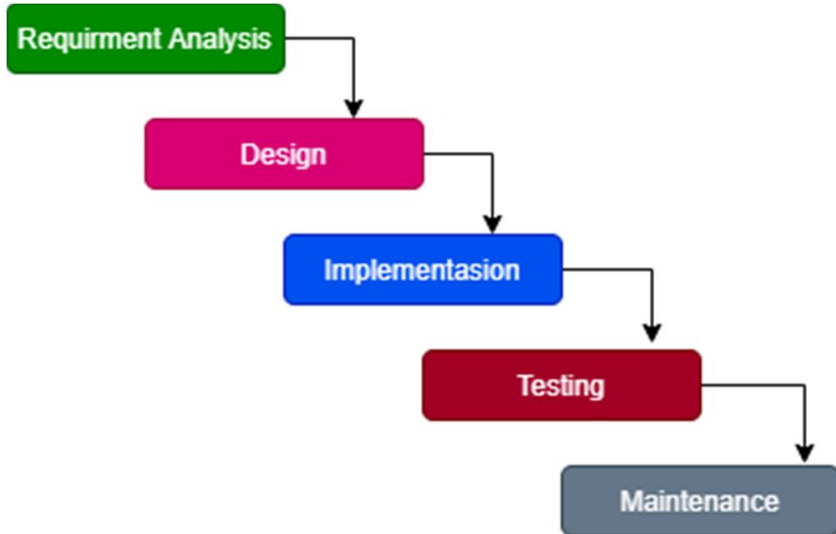

Gambar 1. Waterfall Model

Dibawah ini adalah beberapa proses tahapan desain aplikasi augmented reality sebagai media pembelajaran (Gambar 1).

\subsubsection{Requirement Analysis (Analisis Kebutuhan)}

Tahap ini bertujuan mengetahui seluruh informasi mengenai kebutuhan aplikasi seperti kegunaan aplikasi yang diinginkan oleh pengguna dan batasan aplikasi.

Penelitian ini bertujuan untuk membuat media pembelajaran jadi lebih menarik dengan menggabungkan dengan perkembangan teknologi yang pada saat ini. Penggunaan perkembangan teknologi augmented reality sebagai wadah pembelajaran mengenai sistem pencernaan manusia. Ide penelitian ini didapat dengan pengumpulan studi literatur yang telah dilakukan terkait penelitian.

Kemudian penelitian mebuahkan hasil berupa sebuah aplikasi augmented reality sebagai pemahaman terkait sistem pencernaan pada manusia. Metode yang dipakai pada penelitian ini merupakan metode waterfall.

\subsubsection{Design (Desain)}

Pada tahap desain meupakan tahapan pembuatan alur aplikasi dan membuat tampilan tampilan antarmuka (interface). Tahapan ini sangat penting sebab pada tahap ini yang akan menjadi daya tarik dari suatu aplikasi.

\subsubsection{Implementation (Implementasi)}

Implementasi adalah sebuah penerapan yang sudah disusun secara baik dan sistematis. Implementasi ini dilakukan dengan menggunakan beberapa software tambahan untuk membantu pembuatan aplikasi tersebut.

\subsubsection{Testing (Pengujian)}

Tahapan ini adalah tahapan akhir yaitu pengujian dengan mengecek aplikasi yang sudah sesuai dibuat, mengecek GUI (Graphic User Interface) pada aplikasi dan memastikan tidak adanya error pada aplikasi yang dibuat.

\subsubsection{Maintenance (Pemeliharaan)}

Setelah aplikasi selesai diuji, diperlukan sebuah metode maintenance untuk merawat aplikasi, memperbaiki apabila ditemukan bug pada aplikasi serta untuk melakukan pengikatana pada aplikasi.

\footnotetext{
Akhmad, et., [Algoritma FCD dan NFT Pada Sistem Pencernaan Berbasis AR Menggunakan Single Marker]
} 


\section{3 Fast Corner Detection (FCD)}

Algoritma FCD adalah suatu algoritma dengan cara mendeteksi tiap sudut yang ada pada objek. Tujuannya adalah untuk menurunkan tingkat akurasi deteksi sudut secara langsung [6]. Penggunaan FCD salah satunya untuk meningkatkan fitur ekstraksi. Deteksi objek dipergunakan untuk memilih fitur keistimewaan pada objek[7]. Berikut adalah algoritma FCD.

2.3.1. Ubahlah marker menjadi warna greyscale atau abu - abu, kemudian pilih satu titik kordinat pusat (p) dan berikan nomor dari 1 sampaidengan 16 searah jarum jam.

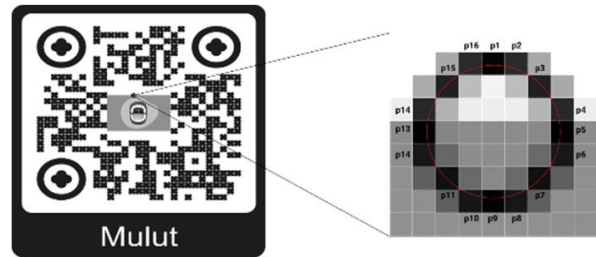

Gambar 2. Memilih Titik Koordinat Pusat (p)

2.3.2. Kemudian pilih empat titik koordinat dengan nilai $n=1, n=2, n=3$ dan $n=4$. Dengan susunan titik koordinat berurutan yaitu (xp, yp+3), (xp+3, yp), (xp, yp-3) dan (xp-3, yp).

$S p \rightarrow x=\{d, I p \rightarrow x \leq I p-t$ (Gelap)

$\{\mathrm{s}, I p-t<I p \rightarrow x<I p+t$ (Normal)

$\{\mathrm{b}$, Ip $+x \leq I p \rightarrow x$ (Cerah)

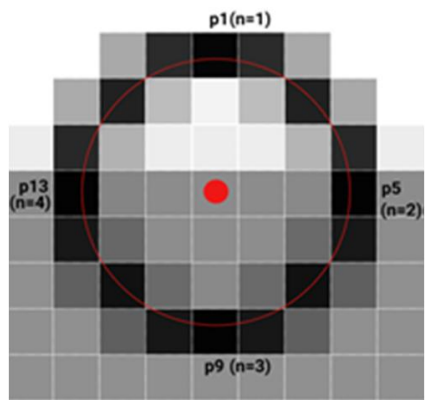

Gambar 3. Titik Koodinat $n=1, n=2, n=3$ dan $n=4$

2.3.3. Setelah itu, bedakan ketajaman pada titik pusat dengan keempat titik koordinat disekitarnya. Jika ada tiga titik koordinat yang memenui, maka titik sudut ialah titik pusat p.

\section{4 Natural Future Tracking}

Natural Feature Tracking (NFT) adalah teknik pendeteksi gambar yang dapat melacak dan mendeteksi fitur khusus yang secara alami terdapat pada gambar yang ingin dideteksi. Fitur tersebut bisa saja garis, sudut, gumpalan dan lain - lain [8].

Ada beberapa perbedaan pendekatan terhadap NFT yaitu seperti SURF, SIFT dan Ferns. Perbedaannya terdapat pada fitur gambar yang digabungkan diantara gambar pada video dan representasi terhadap sebuah objek atau lingkungan yang akan dilacak. 


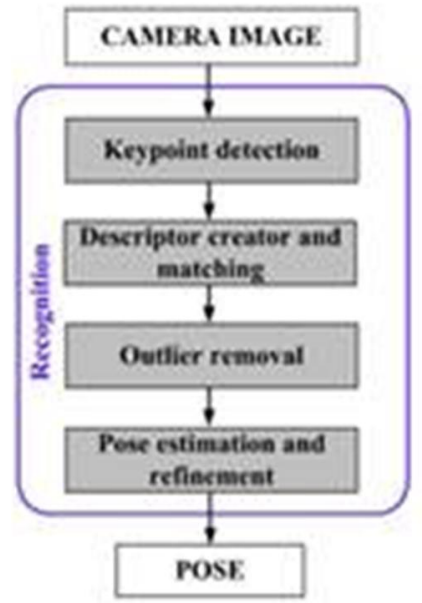

Gambar 4. Step Deteksi Marker

\section{5 Marker Based Tracking}

Marker based tracking adalah media untuk membuat augmented reality yang berupa marker dengan pola unik yang bisa dibaca oleh komputer dengan menggunakan mediainput kamera [9].

\section{6 Marker}

Marker adalah suatu gambar atau image sebagai penanda untuk memunculkan objek tiga dimensi. Ketika sistem tracking pada AR menemukan marker, maka objek yang ada pada marker tersebut akan muncul secara nyata [10].

Penanda Aplikasi yang dibuat pada penelitian ini menggunakan Marker Based Tracking (Single Marker). Single Marker adalah marker yang hanya memiliki satu sisi dan hanya 1 qr code saja. Jadi jika menggunakan single marker sudut pandang (angle) kamera sangat penting karena tidak bisa diliat dari berbagai arah. Di qr code tersebut akan memunculkan object 3d berupa sistem pencernaan manusia serta beberapa penjelasan dari setiap organ yang ada pada sistem pencernaan manusia.

Berikut adalah marker yang dipakai dalam pembuatan aplikasi augmented reality sistem pencernaan manusia.

Tabel 1. Marker dan Rate pada Vuforia

\begin{tabular}{|c|c|c|}
\hline Marker & Objek & Rate \\
\hline Mulut & & \\
\hline & & \\
\hline & & \\
\hline & & \\
\hline
\end{tabular}

Akhmad, et., [Algoritma FCD dan NFT Pada Sistem Pencernaan Berbasis AR Menggunakan Single Marker] 


\begin{tabular}{|l|l|l|}
\hline & & \\
\hline
\end{tabular}

Pada penelitian ini ada 5 objek $3 \mathrm{~d}$ pencernaan, oleh karena itu dibutuhkan pula lima marker. Pada Tabel 1 adalah marker - marker yang diapakai pada penelitian ini, kelima marker tersebut mendapat rate di Vuforia yang sangat baik, yaitu bintang lima. Semakin tinggi rate dari marker, maka marker yang digunakan semakin mudah untuk dideteksi oleh kamera.

\section{7 Flowchart}

Flowchart adalah gambaran dengan menggunakan simbol dari suatu algoritma sebagai media penyelesaian dalam suatu masalah, menggunakan flowchart bisa untuk memudahkan user melakukan vifikasi pada analisis masalah. Flowchart juga memiliki manfaat untuk memfasilitasi komunikasi antara programmer dengan dengan klien [10]. Flowchart dapat membantu untuk mengerti urutan-urutan logika yang rumit. Berikut adalah flowchart dari penelitian ini: 


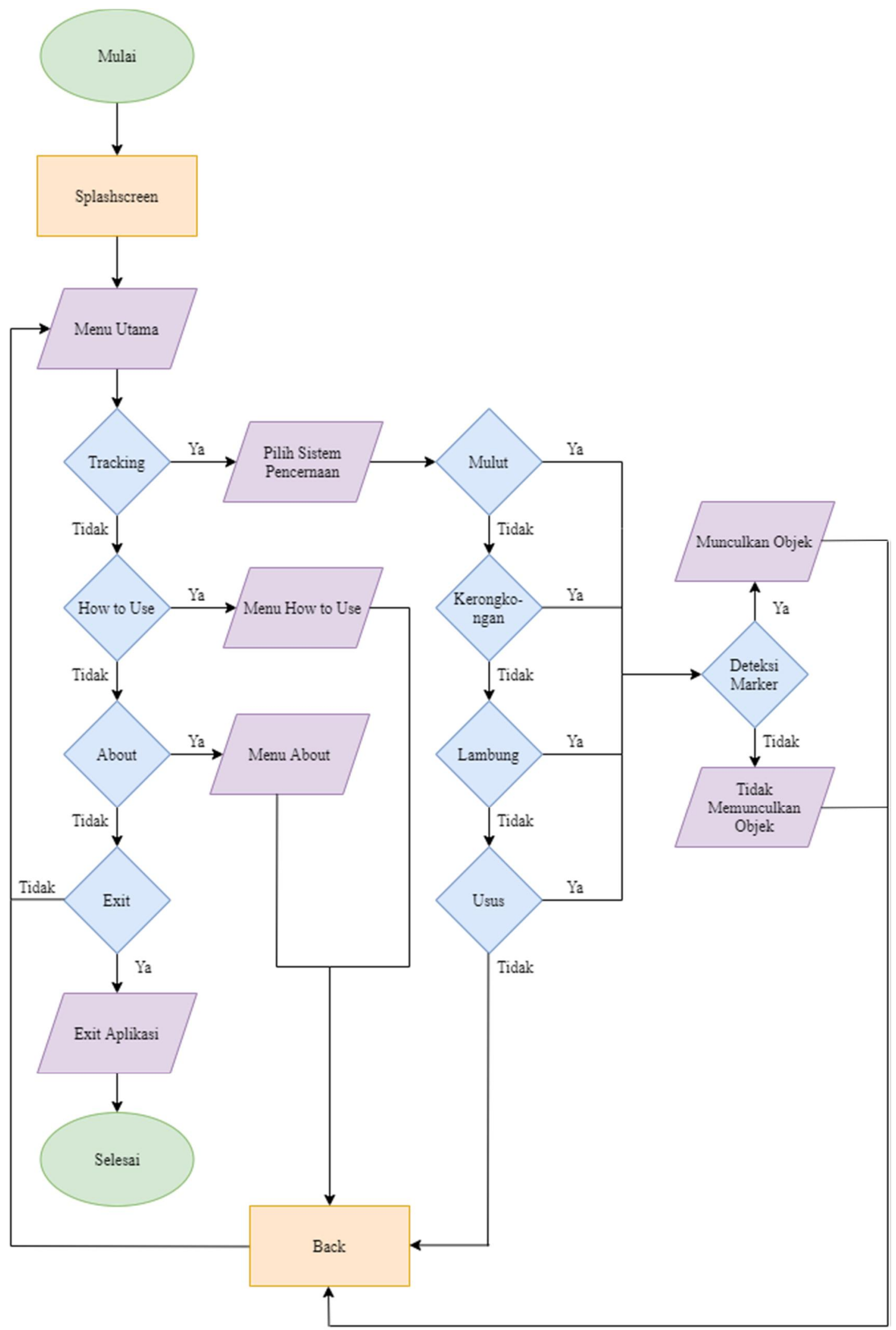

Gambar 5. Flowchart Penelitian 
Pada Gambar 5 menjelaskan alur dari aplikasi. Saat aplikasi dijalankan maka tampilan pertama dari aplikasi tersebut adalah menampilkan menu. Pada menu tersebut terdapat suatu pilihan yaitu Tracking, How to Use dan About.

Ketika menu Tracking yang ditekan maka akan masuk kedalam menu pilihan sistem pencernaan, disini user diminta untuk memilih sistem pencernaan apa yang ingin dimunculkan dalam bentuk augmented reality. Terdapat empat pilihan sistem pencernaan, yaitu mulut, kerongkongan, lambung dan usus.

Jika sudah memilih sistem pencernaan, akan muncul scene AR dan keterangan dari masing - masing sistem pencernaan dan user diminta untuk mengarahkan kamera ponsel ke marker yang sudah disediakan untuk memunculkan objek $3 \mathrm{~d}$.

Ketika menu How to Use yang dipilih maka akan muncul tahapan - tahapan untuk menggunakan aplikasi dan terdapat button untuk mengunduh marker yang dibutuhkan.

Ketika menu About yang ditekan maka akan keluar latar belakang dibuatnya aplikasi tersebut dan ditujukan untuk apa aplikasi dibuat.

\section{HASIL DAN PEMBAHASAN}

\section{1 Implementasi Graphical User Interface (GUI)}

Dalam pembuatan aplikasi, tampilan antarmuka (interface) sangat penting, semakin menarik tampilan antarmuka maka user akan semakin tertarik menggunakan aplikasi tersebut. Berikut adalah antarmuka pada Sistem Pencernaan Berbasis AR.

\subsubsection{Splash Screen}

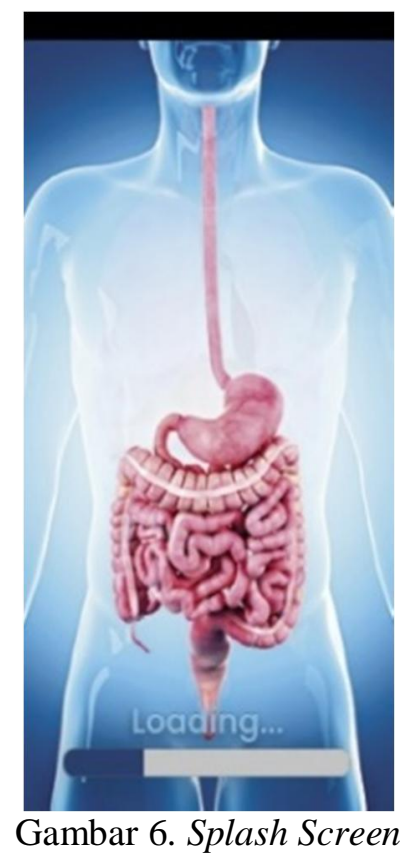

Tampilan awal pada aplikasi sistem pencernaan berbasis AR adalah splash screen atau biasa disebut menu loading. Pada tampilan ini bar loading akan berjalan dari kosong hingga penuh. 


\subsubsection{Menu Utama}

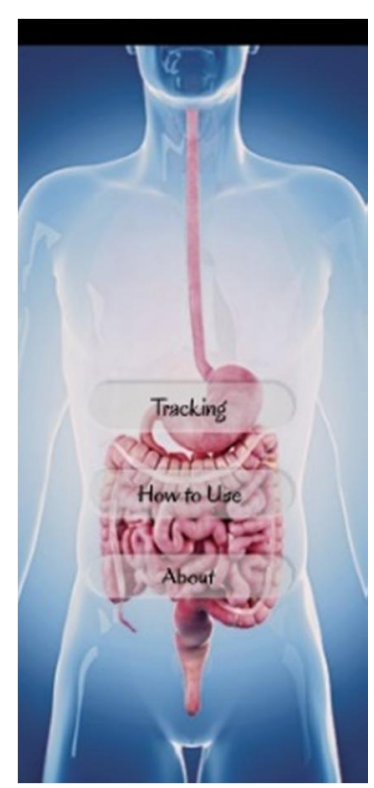

Gambar 7. Menu Utama

Pada tampilan menu utama aplikasi sistem pencernaan berbasis AR terdapat 3 pilihan, yaitu Tracking, How to Use dan About.

\subsubsection{Menu How to Use}

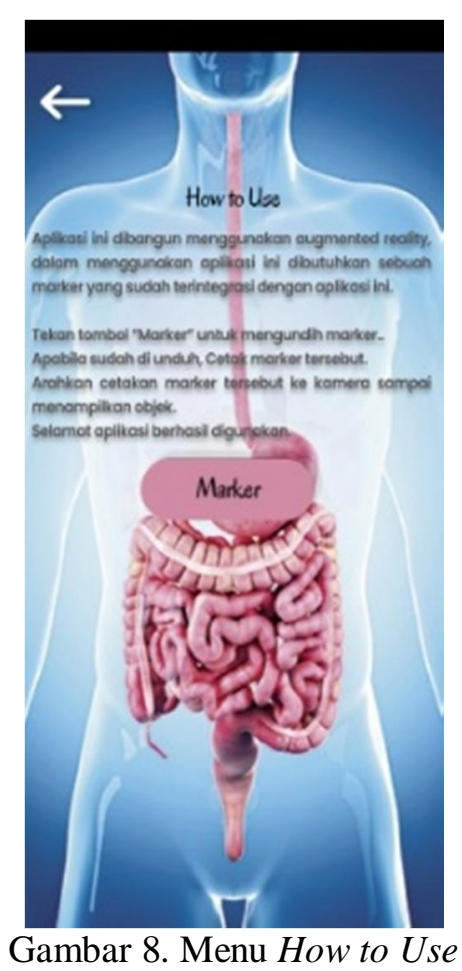

Pada menu How to Use akan ada panduan singkat tentang bagaimana cara menggunakan aplikasi dan terdapat button untuk men-download marker. 


\subsubsection{Menu About}

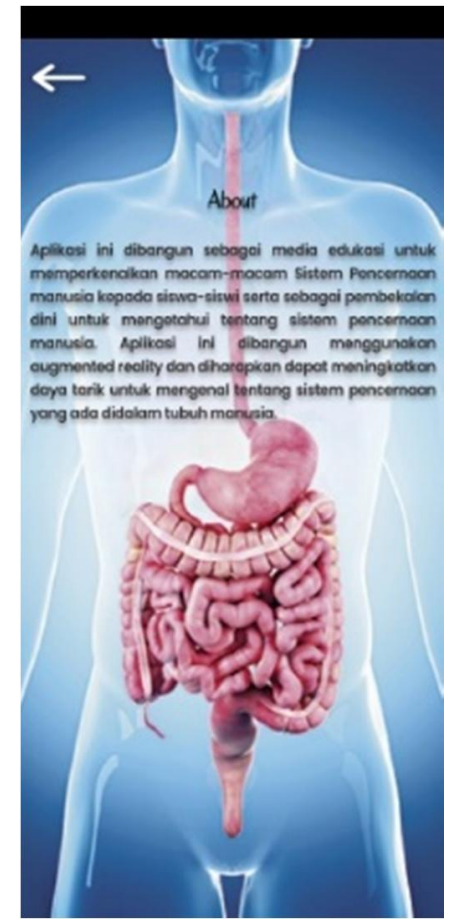

Gambar 9. Menu About

Pada menu About terdapat informasi tentang latar belakang dan tujuan dari pembuatan aplikasi sistem pencernaan berbasis AR.

\subsubsection{Menu Tracking}
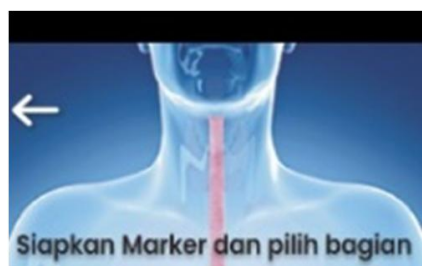
Sistem Pencernaan yang kalian inginkan:

Mulut

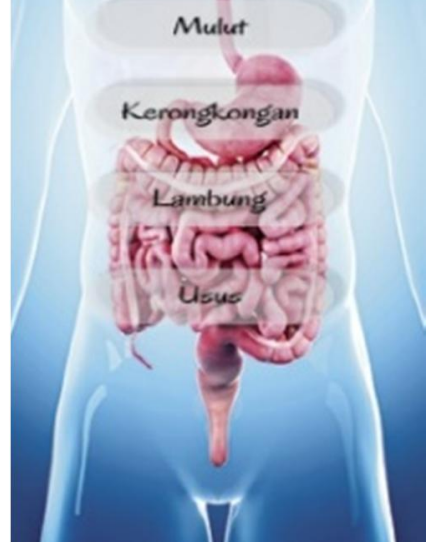

Gambar 10. Menu Tracking 
Pada menu Tracking terdapat 4 pilihan bagian atau organ sistem pencernaan manusia yang bisa ditampilkan objek $3 \mathrm{~d}$ yaitu, mulut, kerongkongan, lambung dan usus.

\subsubsection{Menampilkan Objek}

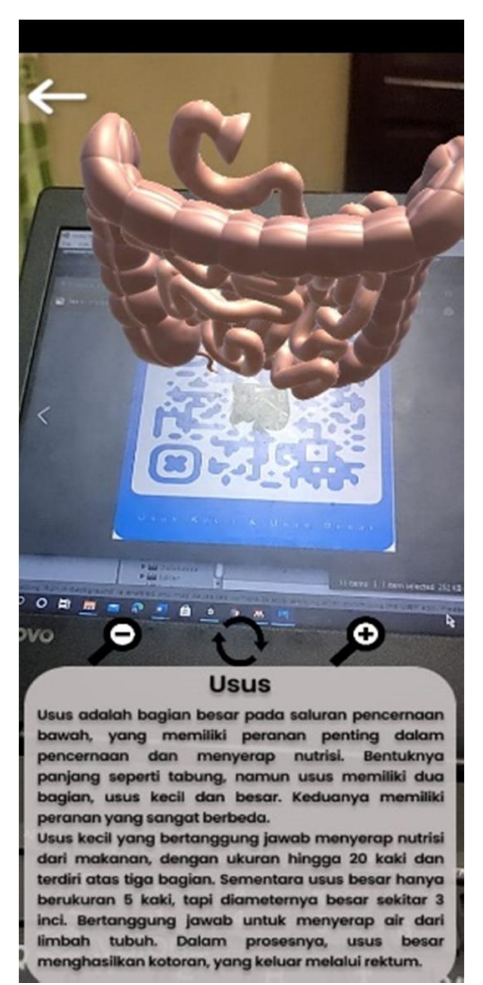

Gambar 11. Tampilan Objek 3d

Pada Gambar 11 diatas adalah contoh ketika marker berhasil dideteksi oleh aplikasi yang dibuat. Jika marker tidak terdeteksi maka objek 3d tersebut tidak akan muncul ketika dideteksi.

\section{2 Pengujian Aplikasi}

Pada pengujian aplikasi ini akan dilakukan dengan memakai tiga device android dengan tingkatan android yang tentu berbeda juga, pengujian dilakukan berdasarkan jarak minimal dan maksimal deteksi marker dan juga waktu respon untuk mendeteksi marker.

Tabel 2. Perangkat Pengujian

\begin{tabular}{cc}
\hline Device & Versi Android \\
\hline Realme XT & $11(\mathrm{R})$ \\
Oppo F7 & $10(\mathrm{Q})$ \\
Xaomi Redmi Note 5 & $9(\mathrm{Pie})$
\end{tabular}

Pada tabel 2 adalah device untuk melakukan pengujian pada aplikasi yang dibuat dalam penelitian ini, device yang digunakan dalam pengujian ini menggunakan tiga versi android yang berbeda sebagai pembanding kesesuaian aplikasi pada tiap - tiap device android.

\section{3 Hasil Pengujian Aplikasi}

Setelah melakukan pengujian menggunakan 3 device berbeda, terdapat beberapa hasil pengujian, yaitu: 
3.3.1. Pengujian Jarak Minimal dan Maksimal

Tabel 3. Hasil Pengujian Jarak

\begin{tabular}{ccc}
\hline Device & Jarak Min & Jarak Maks \\
\hline Realme XT & $\pm 12 \mathrm{~cm}$ & $\pm 100 \mathrm{~cm}$ \\
Oppo F7 & $\pm 12 \mathrm{~cm}$ & $\pm 90 \mathrm{~cm}$ \\
Xaomi Redmi Note 5 & $\pm 12 \mathrm{~cm}$ & $\pm 80 \mathrm{~cm}$
\end{tabular}

Pada Tabel 3, hasil dari pengujian jarak dengan menggunakan tiga device yang berbeda terdapat hasil jarak minimal dan maksimal. Pada device Realme XT, jarak minimal untuk deteksi marker adalah $\pm 12 \mathrm{~cm}$ dan jarak maksimal adalah $\pm 100 \mathrm{~cm}$. Pada device Oppo F7, jarak minimal untuk deteksi marker adalah $\pm 12 \mathrm{~cm}$ dan jarak maksimal $\pm 90 \mathrm{~cm}$. Pada device Xiaomi Redmi Note 5, jarak minimal untuk deteksi marker adalah $\pm 12 \mathrm{~cm}$ dan jarak maksimal $\pm 80 \mathrm{~cm}$.

\subsubsection{Pengujian Waktu Respon}

Tabel 4. Hasil Pengujian Waktu Respon

\begin{tabular}{cc}
\hline Device & Waktu Respon \\
\hline Realme XT & 1,2 detik \\
Oppo F7 & 1,4 detik \\
Xaomi Redmi Note 5 & 1,8 detik
\end{tabular}

Pada Tabel 4, hasil dari pengujian waktu respon untuk menampilkan objek 3D mendapatkan hasil yang berbeda pada ketiga device, namun dari semua hasil tersebut rata - rata waktu respon untuk memunculkan objek cukup singkat yaitu kurang dari 2 detik, setelah objek akan muncul di pada layar device yang digunakan.

\section{KESIMPULAN}

Dari penelitian dan pengujian yang telah dilakukan diatas, berikut adalah beberapa kesimpulan yang bisa diambil: Pertama, pada penelitian ini sudah membuahkan hasil sebuah aplikasi untuk memberi pemahaman edukasi tentang sistem pencernaan manusia khususnya untuk para anak dengan menggunakan AR. Kedua, aplikasi yang dibuat dibangun dengan menggunakan suatu algoritma yang bernama fast corner detection (FCD), dimana algoritma FCD memanfaatkan sudut atau tepi untuk memilih nilai $p$ untuk titik koordinat pusat. Ketiga, pada proses pengujian aplikasi yang telah dilakukan dengan tiga device android yang berbeda yaitu android $11(\mathrm{R}), 10(\mathrm{Q})$ dan 9 (Pie). Dari ketiga device tersebut menghasilkan hasil yang berbeda pula. Pada android 11 mendapat hasil jarak minimal $\pm 12 \mathrm{~cm}$, jarak maksimal $\pm 100 \mathrm{~cm}$ dan waktu respon 1,2 detik. Pada android 10 mendapat hasil jarak minimal $\pm 12 \mathrm{~cm}$, jarak maksimal $\pm 90 \mathrm{~cm}$ dan waktu respon 1,4 detik. Pada android 9 mendapat hasil jarak minimal \pm 12 $\mathrm{cm}$, jarak maksimal $\pm 80 \mathrm{~cm}$ dan waktu respon 1,8 detik.

\section{SARAN}

Saran dari penulis untuk penelitian selanjutnya penulis dapat menggunakan virtual button untuk navigasinya. 


\section{DAFTAR PUSTAKA}

[1] Runtualu, D. \& Purba, Lilana, K. R. Purba. 2015, Media Interaktif Pembelajaran Sistem Pencernaan, Jurnal Infra, 3(2), 103-108.

[2] R. Mauludin, A. S. Sukamto, and H. Muhardi. 2017, Penerapan Augmented Reality Sebagai Media Pembelajaran Sistem Pencernaan pada Manusia Dalam Mata Pelajaran Biologi, J. Edukasi dan Penelit, Inform. Vol. 3, No. 2, p. 117.

[3] Nurhidaya, R., \& Hirawan, D. 2019, Implementasi Animasi Augmented Reality Untuk Pelestarian Situs Bersejarah di Kabupaten Subang, Jurnal Ilmiah KOMPUTASI, 112, 18.

[4] Mustaqim, Ilmawan; Kurniawan Nanang. 2017, Pengembangan Media Pembelajaran Berbasis Augmented Reality, Jurnal Edukasi Elektro, Vol. 1, No. 1.

[5] Wiro Sasmito, G. 2017, Penerapan Metode Waterfall pada Desain Sistem Informasi Geografis Industri Kabupaten Tegal, Jurnal Informatika: Jurnal Pengembangan IT (JPIT), 2(1), 6-12.

[6] A. Willis and Y. Sui. 2009, An Algebraic Model For Fast Corner Detection, Proc. IEEE Int. Conf. Comput. Vis., No. Iccv, pp. 2296-2302.

[7] Abdillah, G. Y., Andryana, S., \& Iskandar, A. 2020, Augmented Reality Sebagai Media Pembelajaran Perangkat Keras Komputer Dengan Fast Corner dan Natural Feature Tracking, JIPI (Jurnal Ilmiah Penelitian dan Pembelajaran Informatika), 5(2), 79.

[8] Yanling, Z., Xixi, C., Lu, Q., \& Pengfei, C. 2019, A New Fast Corner Detection Method Based On Template Matching, IOP Conference Series: Materials Science and Engineering, 563(5).

[9] Setyadi, R., \& Ranggadara, I. 2020, Augmented Reality Using Features Accelerated Segment Test For Property Catalogue, Telkomnika (Telecommunication Computing Electronics and Control), 18(1), 140-147.

[10] Adelia, \& Setiawan, J. 2018, Implementasi Customer Relationship Management (CRM) pada Sistem Reservasi Hotel Berbasisi Website dan Desktop, Universitas Kristen Maranatha, 6(2), 113-126, Bandung.

\footnotetext{
Akhmad, et., [Algoritma FCD dan NFT Pada Sistem Pencernaan Berbasis AR Menggunakan Single Marker]
} 